help in the selection of patients for adjuvant therapy. The choice of index will depend on the surgical staging procedure adopted by a particular centre.

Imperial Cancer Research Fund Clinical Oncolngy Unit,

Guy's Hospital, London SE1 9RT

1 Blamey RW, Elston CW, Ellis IO, Morgan DAL, Maybittle JL. Node negative breast cancer. Br Med f 1990;300:1137. (28 April.)

2 Delides GS, Garas G, Georgouli G, et al. Interlaboratory variation in the grading of breast cancer. Arch Pathol Lab Med 1982;106:126-8.

3 O'Reilly SM, Richards MA. Node negative breast cancer. BrMed f 1989;300:346-8. (10 February.)

4 Leslie MD, Maher EJ. Node negative breast cancer. Br Med $\mathcal{f}$ 1990;300:749. (17 March

5 Early Breast Cancer Trialists' Group. Effect of adjuvant tamoxifen and of cytotoxic therapy on mortality in early breast cancer. N Engl f Med 1988;319:1681-92.

6 O'Reilly SM, Camplejohn RS, Barnes DM, Millis RR, Ruben RD, Richards MA. Node negative breast cancer: prognostic subgroups defined by tumour size and flow cytometry. $f$ Clin Oncol (in press).

\section{Pelvic inflammatory disease}

SIR, - In his recent editorial Mr J Malcolm Pearce highlights the often inadequate diagnosis and treatment of women with pelvic inflammatory disease.' My own study, which was based on a questionnaire sent to individual practitioners requesting details of their management of pelvic inflammatory disease, illustrates the extent of the problem in general practice.

Of 112 general practitioners returning their questionnaires, $94(84 \%)$ provided a combination of antibiotics, $28(25 \%)$ provided antichlamydial treatment, and only four provided combination treatment against Chlamydia trachomatis and Neisseria gonorrhoeae. In total 44 doctors $(40 \%)$ considered investigating or referring male consorts. Only two doctors remarked that they routinely refer for diagnosis all patients with a first attack of pelvic inflammatory disease.

Although optimum management may require admission and diagnostic laparoscopy, this may be impracticable. It might be helpful, therefore, for gynaecologists to develop with genitourinary physicians and general practitioners clear guidelines on treatment and referral to hospital. The evidence so far suggests that the management of pelvic inflammatory disease could be improved greatly.

ANDREW J EYNON-LEWIS

Dartmouth, Devon TQ6 9HT

1 Pearce JM. Pelvic inflammatory disease. $\mathrm{Br} M e d$ f 1990;300: 1090-1. (28 April.)

2 Eynon-Lewis AJ. Audit of the management of pelvic inflammatory disease in general practice. $\mathcal{F} R$ Coll Gen Prac 1988:38:492-3

SIR, - The editorial by Mr J M Pearce' is welcomed by most of us who practise genitourinary medicine, and we hope that it will improve referrals to our specialty. But Mr Pearce fails to emphasise the cost effectiveness of efficient treatment-in terms of misery in patients, morbidity, and precious NHS funds. The pennies spent on antibiotics cannot be compared with the thousands of pounds spent on infertility treatment.

We would also like to point out that $\mathrm{Mr}$ Pearce's advice on treatment for Neisseria gonorrhoea is inappropriate in these days of penicillinase producers and plasmid resistance. Ciprofloxacin or cefuroxime would be more appropriate. Antichlamydial treatment should start concurrently, not as a "two week follow up course," although two weeks' total treatment is essential. Doxycycline, however, would cover both organisms.

Ideally, if pelvic inflammatory disease is suspected it may be prudent to admit the patient to hospital through the department of genitourinary medicine for immediate and approriate antimicrobial tests and contact tracing. Tactful explanation to the patient about this detour is usually well accepted. If such a detour is not possible endocervical swabs for chlamydia and gonorrhoea must be taken and placed in the correct transport media before starting antibiotics, and the patient must be referred as soon as possible. One week and three weeks after admission the patien should return to the department for "tests of cure" and for further counselling. Contact tracing and subsequent treatment of patients' consorts may avert a second attack.

Liaison between gynaecologists and genitourinary physicians greatly enhances the patient's management and greatly reduces morbidity and cost. Why should patients suffer lifelong for a night's pleasure because doctors are reluctant to recognise coitus as the cause of pelvic inflammatory disease?

OLWEN E WILLIAM COLM O'MAHONY

Royal Liverpool Hospital

Liverpool L7 8XP

1 Pearce JM. Pelvic inflammatory disease. $\mathrm{Br}$ Med $\mathcal{F}$ 1990;300: 1090-1. (28 April.)

SIR,-Mr J M Pearce says in his editorial that swabs from the rectum and oropharynx rarely, if ever, add useful evidence to vaginal and urethral swabs.' I agree that cervical and urethral swabs give a high yield of positive results but suggest that rectal swabs should be taken because the recta mucosa is infected in $35-50 \%$ of women with gonococcal cervicitis. ${ }^{23}$

Most rectal infections occur without acknowledged rectal sexual contact. Because the prevalence of rectal infection in women is positively correlated with the duration of endocervical infection ${ }^{4}$ it would seem sensible to screen the rectum for infection when gonococcal pelvic inflammatory disease is suspected. If a sensitive explanation is given acrimony can be averted in most cases. Cervical swabs stained by Gram's method are negative in $40-60 \%$ of women with gonococca salpingitis and examination of rectal swabs by Gram staining may help, therefore, in early identification of the causative organism.

R J COKER

Department of Genitourinary Medicine,

St Mary's Hospital, London W 2 INY

1 Pearce JM. Pelvic inflammatory disease. Br Med $\mathcal{f}$ 1990;300. 1090-1. (28 April.)

1090-1. (28 April.)
Thin RN, Shaw EJ. Diagnosis of gonorrhoea in women. British Thin RN, Shaw EJ. Diagnosis of gonorrh

3 Barlow D, Phillips I. Gonorrhoea in women: Diagnostic, clinical and laboratory aspects. Lancet 1978;i:761.

4 Kinghorn GR, Rashid S. Prevalence of rectal and pharyngeal infection in women with gonorrhoea in Sheffield. British fournal of Venereal Diseases 1979;55:408.

\section{Screening and the 1990 contract}

SIR, - Dr D Slater's concern about the increased load on laboratory services generated by the new contract for general practitioners is pertinent'; there has already been a recent increase from three to four weeks in the reporting time for cervical cytology reports in this district. Dr Slater's estimate for the histopathology resources needed to service increased minor surgery in general practice may, however, be overgenerous. A large proportion of minor surgery will entail procedures such as soft tissue injections which do not use laboratory time.

In my practice, which serves a population of 1900 patients, 104 minor surgical procedures were performed in one year, of which 56 were soft tissue injections; of the remaining 48 , only 24 led to histopathological analysis.
Extrapolating these data to the 70 general practitioners expressing an interest in performing minor surgery in Rotherham, 1680 specimens for histopathology per year would be generated compared with Dr Slater's figure of 4000 . Also, much of the minor surgery would have been carried out previously in hospital, at higher cost. Thus the estimate of extra funding can be reduced further.

N E EARLY

Chesterfield S4O 0ER

1 Slater D. Screening and the 1990 contract. Br.Med f 1990;300 1074. (21 April.)

\section{Management of constipation}

SIR, - Professor $\mathrm{R}$ Taylor mentioned in his recent article that fibre supplements may be used to treat constipation in elderly people. ${ }^{1}$ Constipation is a common symptom in this age group,,$^{2}$ and in sick, immobile old people it is even more common, often accompanied by poor colonic motility and delayed transit times. ${ }^{3}$ In many geriatric units wheat bran is added routinely to the hospital diet.

We investigated the effects of adding $10 \mathrm{~g}$ of wheat bran to the diet of 20 elderly patients (mean age 77 ) who had been in hospital longer than one month and were bed bound. The study included a placebo phase (two weeks), a treatment phase (four weeks), and a second placebo phase (three weeks). Patients and nurses were told that fibre would be added to the diet to control constipation by natural means. This message was reinforced by written information. Menus were simplified to include soups, stews, and porridge to which finely milled bran could be added easily. During the placebo phases food was thickened but no bran was added.

Bran improved stool weight and consistency and reduced the number of days without stools, but faecal incontinence was a frequent and distressing side effect in 10 of 20 patients on bran compared to three on placebo $(\mathrm{p}<0.05)$. Placebo effects on symptoms were prominent in both patients and staff. An earlier study of younger subjects with irritable bowel syndrome also revealed powerful placebo effects. ${ }^{+}$

Frail elderly people may have lax anal sphincters that cannot retain soft or liquid faeces resulting

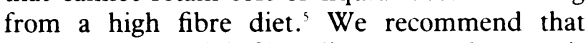
treatment with high fibre diets or supplements is avoided in this group of elderly people.

ME ARDRON A N H MAIN

University Department of Geriatric Medicine,

Selly Oak Hospital,

Birmingham B296jD

1 Taylor R. Management of constipation: high fibre diets work. Br Med f 1990;300:1063-4. (21 April.)

2 Thompson WG, Heaton KW. Functional bowel disorders in apparently healthy people. Gastroenterology 1980:79:283-8.

3 Brocklehurst JC, Kirkland JL, Martin J, Ashford J. Constipation in long stay elderly patients: its treatment and prevention by lactulose, poloxalkol-dihydroanthroquinolone and phosphate enemas. Gerontology 1983;29:181-4.

4 Lucey MR, Clark ML, Lowndes JO, Dawson AM. Is bran efficacious in the irritable bowel sundrome? A double blin placebo controlled crossover study. Gut 1987;28:221-5.

Barratt JA. Effect of wheat bran on stool size. Br Med $\mathcal{f}$ 1988;296:1127-8.

\section{Terminal care in general practice}

SIR,-Dr A C Blyth's audit of terminal care in a training practice noted that all recently bereaved families were visited for counselling' - I fear that such visits are not usually offered.

A study of over 300 recently widowed spouses showed that only $33 \%$ were visited at home by their general practitioners in the five to seven months after bereavement and $24 \%$ were not seen at all General practitioners' views about the need for 